\title{
Electrical, optical and morphological properties of chemically deposited nanostructured tungsten disulfide thin films
}

\author{
P. A. Chate $\cdot$ D. J. Sathe $\cdot$ P. P. Hankare
}

Received: 16 September 2011/Accepted: 24 February 2012/Published online: 14 March 2012

(C) The Author(s) 2012. This article is published with open access at Springerlink.com

\begin{abstract}
Nanocrystalline tungsten disulfide thin films have been deposited on non-conducting glass substrates using triethanolamine bath. The film samples were characterized by X-ray diffraction, scanning electron microscopy, optical spectroscopy and thermoelectric techniques. The crystalline phase of the deposited sample was of hexagonal wurtzite-type. The optical band gap energy of the sample was found to be $1.46 \mathrm{eV}$. The electrical conductivity of the film sample was found to be in the order of $10^{-3}(\Omega \mathrm{cm})^{-1}$. Thermoelectric measurement showed $n$-type of conductivity. The configuration of fabricated cell is $n$-WS $\left|\mathrm{NaI}(2 \mathrm{M})+\mathrm{I}_{2}(1 \mathrm{M})\right| \mathrm{C}_{\text {(graphite) }}$. The efficiency of the cell was found to be $1.29 \%$.
\end{abstract}

Keywords Chalcogenides - Electronic material .

Thin films $\cdot$ Nanomaterial

\section{Introduction}

In the past few years, studies of materials with layered structures such as transition metal dichalcogenides have received an ever increasing attention. This is mainly because of their interesting anisotropic behavior, great

\section{P. A. Chate $(\square)$}

Department of Chemistry, J.S.M. College, Alibag 402 201, India e-mail: pachate04@rediffmail.com; pachate09@rediffmail.com

\section{J. Sathe}

Department of Chemistry, KITs College of Engineering, Kolhapur, Maharashtra, India

P. P. Hankare

Solid State Research Lab, Department of Chemistry,

Shivaji University, Kolhapur 416 004, India diversity in their other physical properties and their usefulness for various applications. Molybdenum and tungsten dichalcogenides constitute structurally and chemically a well-defined family of compounds. $\mathrm{MoS}_{2}, \mathrm{MoSe}_{2}, \mathrm{WS}_{2}$ and $\mathrm{WSe}_{2}$ appear to be very promising semiconducting materials for solar energy conversion (Srivastava 1991; Hulliger 1968; Wilson and Yoffe 1969; Srivasata and Avasthi 1985; Roy and Srivastava 2006). Among the transition dichalcogenides, the stability and non-toxicity of tungsten disulfide makes this layered semiconductor interesting as absorber material in photovoltaic energy conversion. Tungsten disulfide is a layered material consisting of stacked S-W-S slabs. The bonding between the hexagonally arranged sulfur and tungsten atoms in the slabs is very strong whereas the stacked S-W-S slabs are weakly connected by intermolecular of van der Waals forces. The binding energy between S-W-S slabs in c-direction is about $0.14 \mathrm{eV}$ (Rydberg et al. 2003). These nanoparticles play a favorable role as solid lubricant under severe conditions where fluids are unable to support the heavy load (Raport et al. 2005; Raport et al. 1997). They are also used in scanning probe microscopy (Homyonfer et al. 1997), heterogeneous catalysis (Mdleni et al. 1998) and electrochemical hydrogen storage (Chen et al. 2001). $\mathrm{WS}_{2}$ can be synthesized from gas-solid or gas-phase reaction (Yang et al. 2006), pulsed layer deposition ( $\mathrm{Hu}$ et al. 2006) and self-transformation process (Zhang et al. 2007). The properties of thin films and those of single crystal of a material are generally different to that of bulk materials. In thin film form they are strongly dependent on the preparatory techniques used. Hence, it is necessary to characterize the films before they are used in any device (Chandra et al. 1984; Hankare et al. 2006).

We report synthesis of nanocrystalline $\mathrm{WS}_{2}$ thin films by dip method because it is simple, cheap and suitable for 
large area deposition of the thin films. The deposited film samples were characterized by various techniques such as $\mathrm{X}$-ray diffraction, scanning electron microscopy and optical spectroscopy. The electric as well as thermoelectric properties of films are also studied.

\section{Experimental details}

All the chemicals used for the deposition were of analytical reagent grade, including sodium tungstate, triethanolamine, hydrazine hydrate and thiourea.

In actual experimentation, $15 \mathrm{~mL}(0.2 \mathrm{~N})$ sodium tungstate solution was taken in $100 \mathrm{~mL}$ beaker. $5 \mathrm{~mL}$ triethanolamine and $10 \mathrm{~mL}(25 \%)$ hydrazine hydrate solution were added in the reaction bath at $278 \mathrm{~K}$. To this $30 \mathrm{~mL}(0.2 \mathrm{~N})$ thiourea was added and the total volume of the reaction mixture was made up to $80 \mathrm{~mL}$ by adding deionized-water. The beaker was then transferred to ice bath. Cleaned glass slides were positioned vertically. Temperature of the bath was then allowed to increases up to $298 \mathrm{~K}$ slowly. After $5 \mathrm{~h}$, the glass slides were removed from of the bath. The films deposited were washed with double-distilled water, dried in air and kept in desiccators.

\section{Result and discussion}

\section{Deposition mechanism}

Tungsten disulfide films have been deposited by decomposition of thiourea in alkaline solution containing sodium tungstate and triethanolamine as complexing agent. A slow increase in temperature decomposes moderately stable thiourea to yields $\mathrm{S}^{-2}$, while hydrazine hydrate reduces $\mathrm{W}^{+6}$ to $\mathrm{W}^{+4}$ in basic medium. The dissociation of W-TEA complex at higher temperature liberates bear $\mathrm{W}^{+4}$ ions that react with $\mathrm{S}^{-2}$ ion to get tungsten disulfide thin film. The formation of $\mathrm{WS}_{2}$ can be understood from the following reactions;

$$
\begin{aligned}
& \mathrm{W}^{+6}+\mathrm{TEA} \rightarrow\left[\mathrm{W}(\mathrm{TEA})_{3}\right] \\
& {\left[\mathrm{W}(\mathrm{TEA})_{3}\right]+2 \mathrm{NH}_{2}-\mathrm{NH}_{2}+2 \mathrm{OH}^{-} \rightarrow \mathrm{W}^{+4}} \\
& \quad+3 \mathrm{TEA}+2 \mathrm{H}_{2} \mathrm{O}+2 \mathrm{~N}_{2} \uparrow \\
& \mathrm{SC}\left(\mathrm{NH}_{2}\right)_{2}+\mathrm{OH}^{-} \rightarrow \mathrm{SH}^{-}+\mathrm{CH}_{2} \mathrm{~N}_{2}+\mathrm{H}_{2} \mathrm{O} \\
& \mathrm{W}^{+4}+2 \mathrm{~S}^{-2} \rightarrow \mathrm{WS}_{2}
\end{aligned}
$$

Terminal thickness of the film was found to be $0.49 \mu \mathrm{m}$.

X-ray diffraction studies

The X-ray diffractogram of tungsten disulfide thin film was recorded using a Phillips PW-1710 X-ray diffractometer in
$2 \theta$ range from 10 to $80^{\circ}$. Literature survey revealed that tungsten disulfide has two structural phases such as hexagonal and rhombohedral. The X-ray diffraction pattern of as deposited $\mathrm{WS}_{2}$ thin is shown in Fig. 1. Comparison of observed ' $d$ ' with standard ' $d$ ' values confirms that film shows monophased and hexagonal structure (JCPDS-08-0237). A large number of peaks suggested polycrystalline nature of thin films. The XRD pattern shows the highest intensity reflection peak at $d=6.145 \AA$ (002). Along with (002) plane, (101), (006), (110), (114) (116) peaks were also observed. The lattice parameter of hexagonal phase was calculated by using the standard relation. The lattice parameter ' $a$ and $c$ ' of $\mathrm{WS}_{2}$ film was found to be 3.30 and $12.21 \AA$, respectively. These values are in good agreement with the earlier reported ones (Markwell and Halt 1957; Delphine et al. 2005). The crystallite size of tungsten disulfide thin film was calculated by using Scherrer's formula. The average crystallite size was calculated by resolving the highest intensity peak. The average crystallite size of $\mathrm{WS}_{2}$ thin film was found to be $37.4 \mathrm{~nm}$. The microstrain $(\varepsilon)$ developed in the film was calculated from the equation (Hankare et. al 2009);

$\varepsilon=\beta \cos \theta / 4$

where $\beta$ is the full width at half maximum of $(002)$ peak. The microstrain was found to be $6.44 \times 10^{-3}$. The dislocation density $(\rho)$ is estimated according to Williamson and Smallman (Williamson and Smallman 1956) using the relation

$\rho=15 \varepsilon / a D$

where $a$ is the lattice constant and $D$ is the particle size. The dislocation density was found to be $1.68 \times 10^{12} \mathrm{~cm}^{-3}$. The crystallographic data of the $\mathrm{WS}_{2}$ thin films are cited in Table 1 .

Morphological characterization

A study of surface morphology of thin film was done under scanning electron microscope, 250MK-III, Stereoscan,

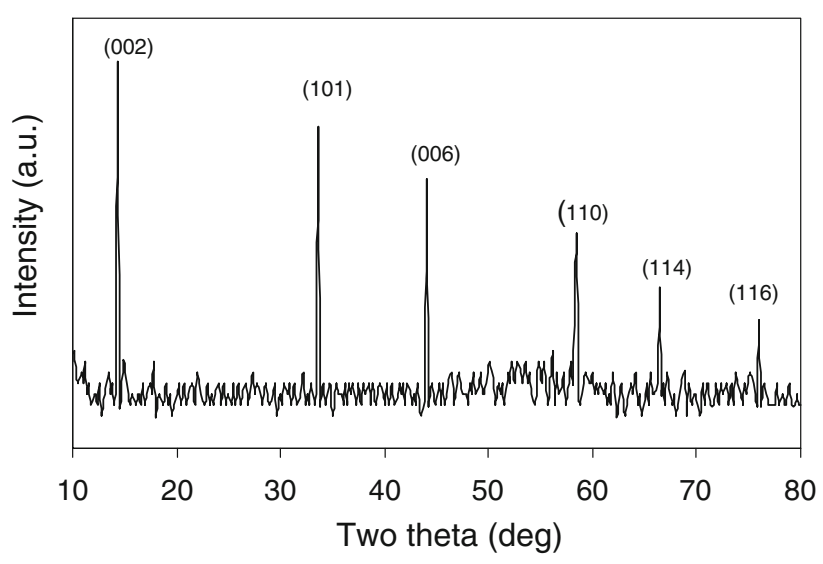

Fig. 1 XRD pattern of $\mathrm{WS}_{2}$ thin film 
Table 1 Crystallographic characterization of $\mathrm{WS}_{2}$ thin film

\begin{tabular}{|c|c|c|c|c|c|c|}
\hline \multirow[t]{2}{*}{ Film } & \multicolumn{2}{|l|}{$d$ values } & \multirow{2}{*}{$\begin{array}{l}\text { hkl } \\
\text { planes }\end{array}$} & \multicolumn{2}{|c|}{ Grain size $(\mathrm{nm})$} & \multirow{2}{*}{$\begin{array}{l}\text { Cell parameter } \\
\text { (A0) }\end{array}$} \\
\hline & Observed & ASTM & & XRD & SEM & \\
\hline \multirow[t]{6}{*}{$\mathrm{WS}_{2}$} & 6.145 & 6.180 & 002 & 37.4 & 40.9 & \multirow{6}{*}{$\begin{array}{l}a=3.30 \\
c=12.21\end{array}$} \\
\hline & 2.665 & 2.667 & 101 & & & \\
\hline & 2.056 & 2.060 & 006 & & & \\
\hline & 1.578 & 1.578 & 110 & & & \\
\hline & 1.406 & 1.405 & 114 & & & \\
\hline & 1.251 & 1.252 & 116 & & & \\
\hline
\end{tabular}

Cambridge, UK. Scanning electron microscopy is an excellent method to study morphology of the sample. The scanning electron micrograph of the 'as deposited' thin film is shown in Fig. 2. The film shows uniform grains and covers the substrate well. The distribution of nodular, spherical grains of almost similar size is observed. Most of the grains are interconnected with each other. This type of morphology is typical of layered structure. The presence of fine background is an indication of one-step growth by multiple nucleations. The average grain size is reported in Table 1.

\section{Optical characterization}

The optical absorption spectrum of film was recorded with UV-VIS-NIR spectrophotometer Hitachi-330 (Japan). The optical absorption spectrum of the as-deposited thin film onto non-conducting glass substrate was studied at room temperature in the wavelength $600-1,000 \mathrm{~nm}$. Figure 3 shows the variation of optical absorption with wavelength. The optical study shows that the films are highly absorptive. The value of absorptivity was found in the range of $104 / \mathrm{cm}$. The value of absorptivity depends upon radiation energy as well as the composition of the film. Based on obtained optical

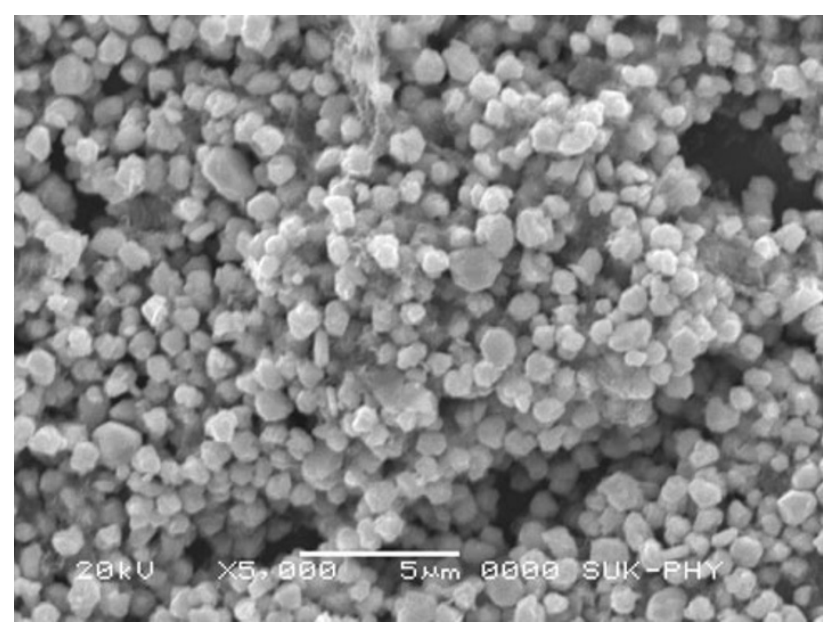

Fig. 2 SEM micrograph of $\mathrm{WS}_{2}$ thin film

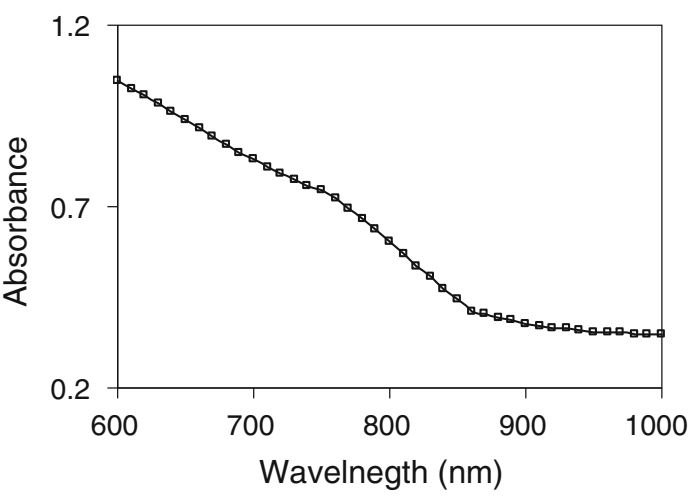

Fig. 3 Absorption spectrum $\mathrm{WS}_{2}$ thin film

absorbance, the square of absorption co-efficient $\left(\alpha^{2}\right)$ is plotted as a function of photon energy $(h v)$ in Fig. 4. It can be seen that the film has a steep optical absorption feature, indicating good homogeneity in the shape and size of the grains and lower defects density near the band edge. As can be seen, $\alpha^{2}$ varies almost linearly with $\mathrm{h} v$ above band gap energy. According to following equation for direct interband transition can be applied (Grahn 1999):

$\alpha^{2}=A\left(h v-E_{\mathrm{g}}\right)^{\mathrm{n}}$

where $A$ is a constant. The band gap energy is obtained by extrapolating the straight line portion of the curve to zero absorption co-efficient. The band gap value of the as deposited $\mathrm{WS}_{2}$ was found to be $1.46 \mathrm{eV}$. The observed value is greater than previously reported value, (Carzmalt et al. 2003) showing a 'blue shift'. This is attributed to size quantization that occurs due to localization of electrons and holes in confined volume of the semiconductor materials.

\section{Electrical characterization}

The electrical conductance measurement was carried out using two-probe method in the temperature range 300-525 K. At room temperature the specific conductance was found to be in the order of $10^{-3}(\Omega \mathrm{cm})^{-1}$. It is

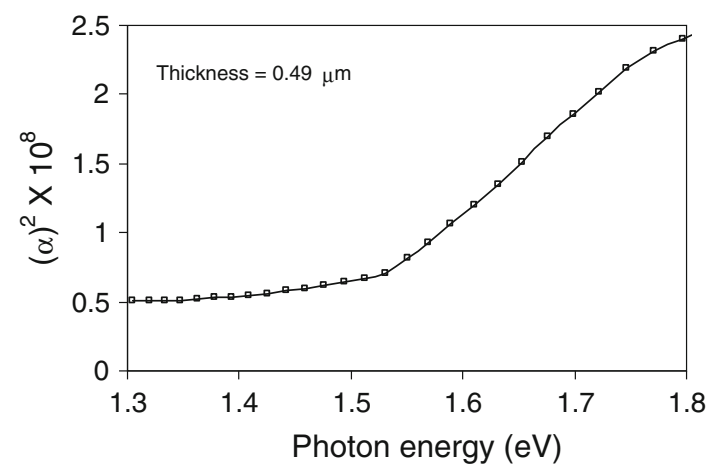

Fig. 4 Plot of $(\alpha)^{2}$ with respect to photon energy

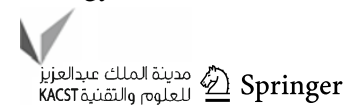




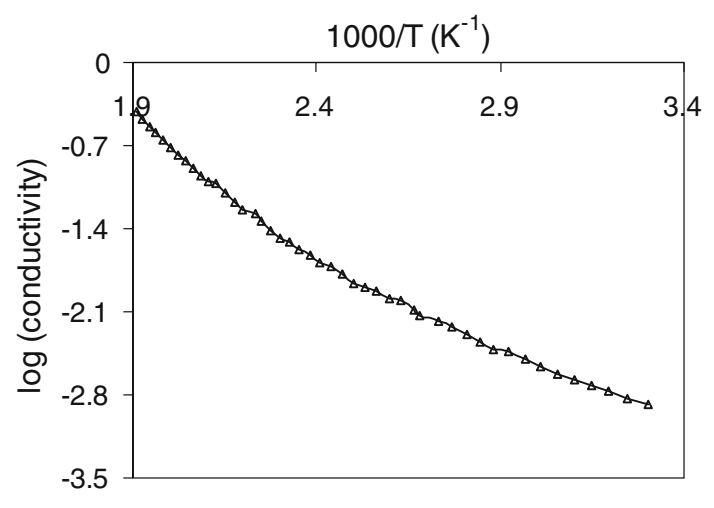

Fig. 5 The variations of $\log$ (conductivity) with inverse temperature

observed that the conductivity of the film increases with increase in temperature. This indicates the semiconducting behavior of the thin film. A plot of $\log$ (conductivity) versus inverse absolute temperature for the cooling and heating curve is shown in the Fig. 5. A plot showing the straight line nature indicates the presence of only one type of conduction mechanism. The activation energy is calculated using exponential form of Arrhenius relation. The activation energy was found to be of $0.468 \mathrm{eV}$. Thermoelectric voltage tests show the layers to be of n-type.

\section{Photoelectrochemical performance}

A PEC cell with configuration $n$-WS $\mathrm{WS}_{2} \mid \mathrm{NaI}(2 \mathrm{M})+\mathrm{I}_{2}$ $(1 \mathrm{M}) \mid \mathrm{C}_{\text {(graphite) }}$ was formed. Figure 6 shows the photovoltaic power putout characteristics for a cell under illumination of $30 \mathrm{~mW} / \mathrm{cm}^{2}$. The maximum power output of the cell is given by the largest rectangle that can be drawn inside the curve. The open-circuit voltage and short-circuit current are found to be $428 \mathrm{mV}$ and $367 \mu \mathrm{A}$, respectively. The power conversion efficiency is found to be $1.29 \%$.

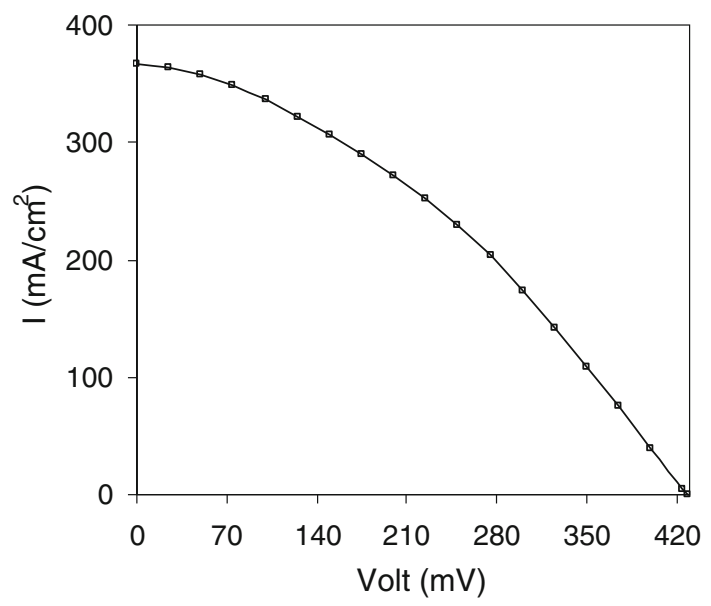

Fig. 6 Power output curves for $\mathrm{WS}_{2}$ photoelectrode

\section{Conclusions}

1. Binary $\mathrm{WS}_{2}$ thin films were grown onto nonconducting glass substrates by using dip method.

2. The average grain size of $\mathrm{WS}_{2}$ films was found to be $40.9 \mathrm{~nm}$.

3. Temperature dependence of electrical conductivity shows that semiconducting nature of films.

4. The material shows promising photo-response when tested in iodine-iodide electrolyte.

Open Access This article is distributed under the terms of the Creative Commons Attribution License which permits any use, distribution, and reproduction in any medium, provided the original author(s) and the source are credited.

\section{References}

Carzmalt CJ, Parkin IP, Peters ES (2003) Atmospheric pressure chemical vapour deposition of WS2 thin films on glass. Polyhedron 22:1499

Chandra S, Singh DP, Srivastava DC, Sahu SN (1984) Electrodeposited semiconducting molybdenum selenide films. II. Optical, electrical, electrochemical and photoelectrochemical solar cell studies. J Phys D Appl Phys 17:2125

Chen J, Kuriyama N, Yuan H, Takeshita H, Saki T (2001) Electrochemical hydrogen storage in $\mathrm{MoS}_{2}$ nanotubes. J Am Chem Soc 123:11813

Delphine SM, Jayachandran M, Sanjeeviraja C (2005) Pulsed electrodeposition and characterization of molybdenum diselenide thin film. Mater Res Bull 40:135

Grahn HT (1999) Introduction to semiconductor physics. World scientific publishing, Singapore

Hankare PP, Chate PA, Delekar SD, Bhuse VM, Asabe MR, Jadhav BV, Garadkar KM (2006) Structural and opto-electrical properties of molybdenum diselenide thin films deposited by chemical bath deposition. Cryst Growth 291:40

Hankare PP, Chate PA, Sathe DJ, Chavan PA, Bhuse VM (2009) Effect of thermal annealing on properties of zinc selenide thin films deposited by chemical bath deposition. J Mater Sci Mater Electron 20:374

Homyonfer M, Alperson B, Rosenberg Y, Sapir L, Cohen SR, Hodes $G$ (1997) Intercalation of inorganic fullerene-like structures yields photosensitive films and new tips for scanning probe microscopy. J Am Chem Soc 119:2693

Hu J, Zabinski J, Sanders J, Bultman J, Voevodin A (2006) Pulsed laser syntheses of layer-structured WS2 nanomaterials in water. J Phys Chem B 110:8914

Hulliger F (1968) Crystal chemistry of the chalcogenides and pnictides of the transition elements. Struct Bond 4:83

Markwell DR, Halt ML (1957) A study of cathode potentials in aqueous tungstate solutions. J Electrochem Soc 104:488

Mdleni M, Hyeon T, Suslick K (1998) Sonochemical synthesis of nanostructured molybdenum sulfide. J Am Chem Soc 120:6189

Raport L, Bilik Y, Feldman Y, Homyonfer M, Cohen SR, Tenne R (1997) Hollow nanoparticles of $\mathrm{WS}_{2}$ as potential solid-state lubricants. Nature 387:791

Raport L, Feischer N, Tenne R (2005) Applications of $\mathrm{WS}_{2}\left(\mathrm{MoS}_{2}\right)$ inorganic nanotubes and fullerene-like nanoparticles for solid lubrication and for structural nanocomposites. J Mater Chem $15: 1782$ 
Roy P, Srivastava SK (2006) Chemical bath deposition of $\mathrm{MoS}_{2}$ thin film using ammonium tetrathiomolybdate as a single source for molybdenum and sulphur. Thin Solid Films 496:293

Rydberg H, Dion M, Jacobson N, Schroder E, Hyldgarrd P, Simak SI, Langreth DC, Lundqvist BJ (2003) Vanderwaals density functional for layered structures. Phys Rev Lett 91:126402

Srivasata SK, Avasthi BN (1985) Layer type tungsten dichalcogenide compounds: their preparation, structure, properties and uses. J Mater Sci 20:3801

Srivastava SK (1991) Structural and morphological studies on indium intercalated compounds of molybdenum disulphide; $\operatorname{In}_{\mathrm{x}} \mathrm{MoS}_{2}$ $(0<\mathrm{x}<1)$. Mater Res Bull 26:631
Williamson GB, Smallman RC (1956) Dislocation densities in some annealed and cold-worked metals from measurements on the X-ray debye-scherrer spectrum. Philos Mag 1:34

Wilson JA, Yoffe AD (1969) The transition metal dichalcogenides discussion and interpretation of the observed optical, electrical and structural properties. Adv Phys 18:193

Yang H, Liu S, Li J, Li M, Peng G, Zou G (2006) Synthesis of inorganic fullerene like- $\mathrm{WS}_{2}$ nanoparticles and their lubricating performance. Nanotechnology 17:1512

Zhang L, Tu J, Wu H, Yang Y (2007) WS2 nanorods prepared by self-transformation process and their tribological properties as additive in base. Mater Sci Eng A 454:487 